\title{
Normocalcemic Primary Hyperparathyroidism: Need for a Standardized Clinical Approach
}

\author{
Guido Zavatta ${ }^{1}$, Bart L. Clarke ${ }^{2}$ \\ ${ }^{1}$ Division of Endocrinology and Diabetes Prevention and Care, IRCCS Azienda Ospedaliero-Universitaria di Bologna, \\ Department of Medical and Surgical Sciences (DIMEC), Alma Mater Studiorum University of Bologna, Bologna, Italy; \\ ${ }^{2}$ Division of Endocrinology, Diabetes, Metabolism, and Nutrition, Mayo Clinic, Rochester, MN, USA
}

Since normocalcemic primary hyperparathyroidism (NHPT) was first defined at the Third International Workshop on the Management of Asymptomatic Primary Hyperparathyroidism in 2008, many papers have been published describing its prevalence and possible complications. Guidelines for the management of this condition are still lacking, and making the diagnosis requires fulfillment of strict criteria. Recent studies have shown that intermittent oscillations of serum calcium just below and slightly above the normal limits are very frequent, therefore challenging the assumption that serum calcium must be consistently normal to make the diagnosis. There is debate if these variations in serum calcium outside the normal range should be included under the rubric of NHPT or, rather, a milder form of classical primary hyperparathyroidism. Innovative approaches to define NHPT have been proposed that still need to be validated in prospective studies. Non-classical complications, especially cardiovascular complications, have been associated with NHPT, indicating that hyperparathyroidism may be a cardiovascular risk factor. New associations between parathyroid hormone (PTH) and several other comorbidities have also been reported from observational studies, suggesting that excessive PTH secretion might cause tissue dysfunction independent of serum calcium. Heterogeneous studies using different definitions of NHPT, however, make it difficult to draw definitive conclusions regarding the role of PTH excess when complications other than osteoporosis or kidney stones are described. This review will focus on clinical aspects and suggest an approach to NHPT.

Keywords: Hyperparathyroidism; Osteoporosis; Nephrolithiasis; Parathyroid surgery; Calcium; Parathyroid hormone

\section{INTRODUCTION}

The era of precision medicine requires that all criteria for a given diagnosis be met precisely. This is because a correct diagnosis of a disease has certain implications, and the same disease might have variable treatment options for a given patient. These considerations apply to primary hyperparathyroidism (PHPT), given that the term "primary" implies parathyroid gland autonomy. Parathyroid gland autonomy needs to be established by the endocrinologist during the evaluation of patients suspected of

Received: 16 April 2021, Revised: 30 April 2021, Accepted: 3 May 2021

Corresponding author: Bart L. Clarke

Division of Endocrinology, Diabetes, Metabolism, and Nutrition, Mayo Clinic E18-A, 200 1st Street SW, Rochester, MN 55905, USA

Tel: +1-507-266-4322, Fax: +1-507-284-5745, E-mail: clarke.bart@mayo.edu having PHPT.

PHPT is well known to present with different phenotypes [1]. These include the moderately symptomatic phenotype that is less common in the modern era, as well as the mildly symptomatic and asymptomatic phenotypes. The newly defined normocalcemic variant has become a focus of interest among endocrinologists interested in parathyroid disorders and among surgeons with expertise in parathyroid surgery. This newer variant has generated new questions regarding diagnosis and clinical management.

\section{Copyright $\odot 2021$ Korean Endocrine Society}

This is an Open Access article distributed under the terms of the Creative Commons Attribution Non-Commercial License (https://creativecommons.org/ licenses/by-nc/4.0/) which permits unrestricted non-commercial use, distribution, and reproduction in any medium, provided the original work is properly cited. 
Normocalcemic primary hyperparathyroidism (NHPT) was first recognized in the Third International Workshop on Parathyroid Disorders in 2008 [1]. A multitude of manuscripts has been published on the prevalence and possible complications of NHPT since then, but consensus guidelines for management are still lacking because the diagnosis requires fulfillment of strict criteria, which were not followed in many of the retrospective observational studies. These studies have been highly heterogeneous in terms of patient selection. As a result, a consensus is lacking regarding whether the same criteria should be used for referral of patients with NHPT for surgery as are used for patients with mild PHPT, as well as regarding whether surgery improves outcomes compared to observation in patients with NHPT who have classical complications of PHPT, including osteoporosis and kidney stones.

While PHPT classically requires the presence of increased serum calcium with increased or inappropriately high-normal parathyroid hormone (PTH) values, NHPT requires persistently normal serum calcium and consistently high serum PTH levels. This means that only abnormal PTH levels are required to make the diagnosis, yet serum PTH levels may be affected by many other factors that must be excluded before labeling persistent hyperparathyroidism as NHPT.

This review will focus on the diagnosis and clinical implications of NHPT and summarize recent findings on this topic.

\section{Diagnosis}

The Fourth International Workshop on the Management of Asymptomatic Primary Hyperparathyroidism in 2014 [2] further defined the consensus definition of NHPT. The diagnosis of NHPT is based on persistently high serum PTH levels in the setting of persistently normal serum total and ionized calcium levels, measured at least three times consecutively over a period of 3 to 6 months, after secondary causes of increased serum PTH have been excluded [3]. The exclusion of secondary causes of hyperparathyroidism may have been overlooked in some of the retrospective observational studies, thereby leading to conflicting results regarding complications of this disorder. Dietary calcium intake, vitamin D status, malabsorption, and medications such as bisphosphonates, denosumab, thiazide diuretics, and lithium are known to affect serum calcium and/or PTH levels. Potential confounders should either be avoided or, if clinically possible, corrected or discontinued to confirm the diagnosis of NHPT. Renal dysfunction with an estimated glomerular filtration rate $<60 \mathrm{~mL} / \mathrm{min}$ may be a potential cause of increased serum PTH levels. Excessive urinary calcium excre- tion must also be ruled out, as hypercalciuria may secondarily stimulate PTH over-secretion [4].

Of the factors mentioned, dietary calcium intake and intestinal absorption commonly lead to variability in laboratory measurements because of day-to-day variation. Dietary calcium intake is highly heterogeneous across the population, although the U.S. Institute of Medicine (IOM) guidelines recommended agespecific thresholds, which should normally be met to exclude secondary hyperparathyroidism [5]. Although calcium intake can be estimated during proper nutritional counseling, it can vary over days and months, and calcium absorption can vary with vitamin D status. Serum 25-hydroxyvitamin D (25(OH)D) is a good marker of nutritional vitamin D status, which is inversely associated with serum PTH levels in population-based studies [6]. However, different thresholds for normal serum $25(\mathrm{OH}) \mathrm{D}$ have been proposed by different societies. The minimum serum level of $20 \mathrm{ng} / \mathrm{mL}$ is favored by some societies and countries, whereas a minimum of $30 \mathrm{ng} / \mathrm{mL}$ is favored in the United States and other countries. The latter was favored for diagnosis of NHPT in recommendations from the Fourth International Workshop on the Management of Asymptomatic Primary Hyperparathyroidism [7]. Intestinal malabsorption is quite common and is caused by conditions that might impair calcium or vitamin D absorption by the gut. When intestinal malabsorption has not been formally diagnosed previously, 72-hour stool fat is commonly used as a screening test, with $>7 \mathrm{~g}$ of stool fat used to diagnose malabsorption. Other laboratory indices are also readily available to assess patients with malabsorption, including serum iron, vitamin B12, vitamin D, and trace elements, but this diagnosis may easily be overlooked in patients not complaining of malabsorptive symptoms such as unexplained weight loss, diarrhea, or gastrointestinal complaints.

Two technical difficulties may make it more difficult to confirm a precise diagnosis during daily clinical practice. First, laboratory assays of serum $25(\mathrm{OH}) \mathrm{D}$ may have poor precision due to large coefficients of variation, making it difficult to rule out vitamin D deficiency [8]. Second, serum ionized calcium requires rapid processing after it is drawn, which may be impossible in the usual clinical setting.

For all these reasons, it is difficult for clinical endocrinologists to be confident of a diagnosis of NHPT, because other clinical conditions need to be ruled out first, and this is not always easy.

There may still be a zone of uncertainty, however, between PHPT and NHPT. This zone includes patients with serum calcium persistently in the upper-normal range, along with increased PTH levels, with normal serum 25(OH)D and 24-hour urine 
calcium. These patients could have either NHPT or PHPT. Interpreting the serum calcium level in this situation is not always easy. Patients with upper-normal serum calcium levels and increased serum PTH could be considered to have serum calcium inappropriate for their PTH levels, and therefore be diagnosed with very mild PHPT, or they could be diagnosed with NHPT. Some authors have proposed that in these cases an increased serum calcium/phosphate ratio might be helpful in confirming parathyroid gland autonomy, although this tool still needs to be validated in prospective studies [9].

\section{Diagnosis of NHPT: least significant change of serum calcium measurement}

Further debate regarding the diagnosis of NHPT was generated in 2020 with publication of the manuscript by Schini et al. [10] from the University of Sheffield (UK) [11,12]. After observing that serum calcium levels oscillate with time, and sporadically exceed the upper limit of the normal range, raising the likelihood of classical PHPT, these authors proposed a new approach to defining NHPT [13] that makes use of the least significant change (LSC) of albumin-adjusted serum calcium. The LSC is widely used in quantitative assessment of changes in bone mineral densitometry over time, and in the assessment of changes in bone turnover markers over time, as well as other biological parameters. If a parameter can be measured quantitatively, LSC may be used to establish whether the previous value of a given parameter is significantly different from the value obtained in follow-up in the same subject. The LSC is calculated by multiplying the within-subject standard deviation of albumin-adjusted serum calcium by 2.77 [14]. Schini et al. [10] obtained an LSC of $0.25 \mathrm{mmol} / \mathrm{L}$ or $1.0 \mathrm{mg} / \mathrm{dL}$ for serum calcium using the UK Biobank database. The authors suggested that there are two important implications of this calculation. First, intermittent hypercalcemia within the LSC would provide a new definition of NHPT, thus altering the accepted definition of NHPT that requires persistently normal serum calcium levels. Second, this new calculation could be helpful in excluding the persistence of disease early after parathyroidectomy. Although PTH levels might still be elevated after parathyroidectomy in NHPT, a significant decrease in serum calcium beyond the LSC would be reassuring of a surgical cure. However, these hypotheses require validation in a prospective study. Fig. 1 shows a graphical representation of the LSC.

\section{Prevalence}

To obtain a general estimate of the prevalence of NHPT, popula-

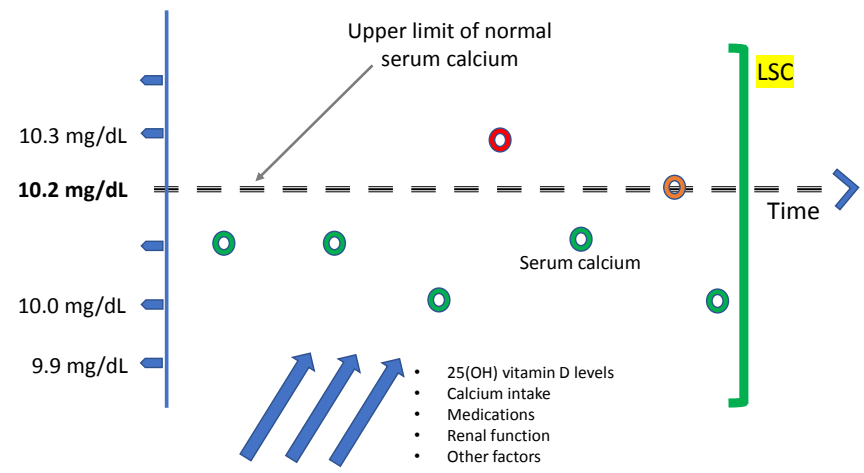

Fig. 1. Ambulatory patients with normocalcemic primary hyperparathyroidism (NHPT) typically present with upper-normal serum calcium levels, which may be occasionally be slightly above the upper limit of the normal range if biochemical measurements are collected serially over time. It is not yet clear whether this biochemical pattern is associated with classical or non-classical complications, or whether parathyroidectomy reduces the risk of bone loss or kidney stones. Prospective studies are needed to clarify these issues. The green bar on the right represents the proposed method [13] to identify patients with NHPT, which requires that albumin-adjusted serum calcium be normal and remain within the least significant change (LSC) over 3 to 6 months. This proposed definition of NHPT contrasts with that of the Fourth International Workshop on the Management of Asymptomatic Primary Hyperparathyroidism, in which serum calcium levels must remain persistently within normal limits. 25(OH), 25-hydroxyvitamin.

tion-based studies that analyzed serum calcium and PTH need to be considered. Theoretically, these studies should lack major selection bias, but this is difficult to avoid in smaller endocrine and surgery case series. Based on the best studies available, the prevalence of NHPT appears to range from $0.4 \%$ to $0.6 \%$ $[15,16]$. It should be noted that these population-based studies did not rely on the strict diagnostic criteria, requiring several repeated measurements of PTH, proposed by the Fourth International Workshop on Asymptomatic Primary Hyperparathyroidism. Therefore, there is a reasonable chance that this estimate includes some patients with unrecognized secondary hyperparathyroidism. Population-based studies reported that classical complications of PHPT, such as fragility fractures, osteoporosis, increased bone turnover markers, and kidney stones had similar frequencies and patterns to those seen in the general population [15,17-19]. Moreover, when patients with NHPT were reassessed longitudinally [15], 75\% of cases with an initial diagnosis of NHPT could not be confirmed after a follow-up of up to 8 years, thus increasing the possibility that patients were originally misclassified and had a form of secondary hyperparathyroidism. 


\section{Complications of NHPT}

Once hyperparathyroidism has been diagnosed, assessment of serum calcium becomes important in confirming or excluding NHPT. Notably, serum calcium can be measured as total calcium, albumin-adjusted total calcium, or ionized calcium. Most studies have used different assays and criteria to define normal serum calcium. Nevertheless, independent of how normal serum calcium is defined, rates of complications are highly variable across referral cohorts [20-31]. Table 1 shows classical complication rates in referral cohorts of NHPT according to how serum calcium was assessed.

NHPT has been associated with several medical complications. The classical complications of hyperparathyroidism, as well as a variety of putative associations supported by observational studies, are summarized here.

\section{CLASSICAL COMPLICATIONS}

\section{Loss of bone mineral density and fractures}

No studies have been conducted on the incidence of fractures in patients with NHPT. NHPT cohorts have been selected in referral centers based on decreased bone mineral density (BMD) and classified either as osteopenia or osteoporosis. As a result, all patients in these studies had low BMD (Table 1). These cohorts raise the possibility that increased serum PTH in the setting of normal serum calcium, without identified secondary causes of bone loss, may cause bone loss. If patients with NHPT have low $\mathrm{BMD}$, following these patients longitudinally might unveil a further decrease in their BMD.

A 10-year prospective observational study was carried out in patients with PHPT starting in 1999 at Columbia University in
New York City [32]. In this study, of a total of 121 patients with classical PHPT, 52 asymptomatic patients did not undergo parathyroid surgery and were followed long-term. Eleven of these 52 patients $(21 \%)$ had a decrease in their BMD at one or more sites of at least $10 \%$ over the 10 -year interval. These 11 patients with significant bone loss had higher mean serum calcium levels at baseline than those in whom BMD remained stable. Mean baseline serum calcium level in the patients with stable BMD over the 10 years was $10.3 \pm 0.4 \mathrm{mg} / \mathrm{dL}$, while in the patients whose BMD decreased, mean serum calcium at baseline was $10.7 \pm 0.5 \mathrm{mg} / \mathrm{dL}$. It may be that a milder clinical phenotype, with serum calcium levels resembling those in NHPT, might not be associated with decreased BMD over time. This could be interpreted as implying that patients with NHPT with high-normal serum calcium levels might also benefit from a conservative approach, with periodic monitoring of serum calcium to detect progression of hyperparathyroidism toward a more severe phenotype.

The most well-defined and comprehensive study of NHPT to date is the prospective cross-sectional study by Palermo et al. [30]. This study evaluated three groups of patients enrolled consecutively: 41 patients with PHPT, 47 patients with NHPT, and 39 age- and sex-matched controls. Patients classified as having NHPT met the definition described by the Fourth International Workshop on Asymptomatic Primary Hyperparathyroidism criteria [7]. Bone density values at all sites in the NHPT patients were found to lie between those in the PHPT patients and healthy controls. Of note, BMD at the lumbar spine, femoral neck, total hip, and one-third distal radius was no different than in the controls. In comparison, BMD at all sites was lower in PHPT patients compared to controls. No statistical differences

Table 1. Frequency of Classical Complications Based on the Method Used to Define Normal Serum Calcium in Major Referral Cohorts of Normocalcemic Primary Hyperparathyroidism

\begin{tabular}{|c|c|c|c|c|}
\hline & Total calcium & Albumin-adjusted calcium & $\begin{array}{c}\text { Albumin-adjusted and } \\
\text { ionized calcium }\end{array}$ & $\begin{array}{l}\text { Total calcium and ionized } \\
\text { calcium }\end{array}$ \\
\hline \multirow{4}{*}{$\begin{array}{l}\text { Osteoporosis, fractures, or } \\
\text { bone loss }\end{array}$} & Amaral et al. [20] (15\%) & Tordjman et al. [22] (38\%) & Palermo et al. [30] (28\%) & Maruani et al. [21] (18\%) \\
\hline & Cakir et al. [28] (47\%) & Lowe et al. [24] (57\%) & Silverberg et al. [23] (45\%) & Wade et al. [25] (25\%) \\
\hline & Siprova et al. [29] (42\%) & Koumakis et al. [26] (92\%) & & \\
\hline & Marques et al. [27] (36\%) & & & \\
\hline \multirow[t]{4}{*}{ Nephrolithiasis } & Amaral et al. [20] (18\%) & Tordjman et al. [22] (9\%) & Palermo et al. [30] (13\%) & Maruani et al. [21] (35\%) \\
\hline & Siprova et al. [29] (4\%) & Lowe et al. [24] (14\%) & Silverberg et al. [23] (14\%) & Wade et al. [25] (25\%) \\
\hline & Marques et al. [27] (29\%) & Koumakis et al. [26] (18\%) & & \\
\hline & & Lemos et al. [31] (20\%) & & \\
\hline
\end{tabular}


were found between BMD in NHPT and PHPT, except for a lower BMD value at the one-third distal radius in PHPT. Vertebral fractures detected by vertebral fracture assessment were far more common in patients with PHPT (60\%) compared to NHPT $(28 \%)$ or controls $(23 \%)$. Markers of bone turnover (serum carboxy-terminal [CTx]-telopeptide of type 1 collagen and procollagen type $1 \mathrm{~N}$-terminal propeptide $[\mathrm{P} 1 \mathrm{NP}]$ ) were progressively higher in controls, NHPT, and PHPT, with statistical differences observed between markers in PHPT and NHPT. The authors concluded that NHPT may be considered as an intermediate phenotype between classical PHPT and controls in terms of biochemical factors, but that increased bone complications, including BMD loss, increased vertebral fractures, or bone turnover abnormalities, could not be demonstrated.

Therefore, the treatment of osteoporosis in NHPT should not be different from routine osteoporosis therapy, although anabolic therapy with teriparatide or abaloparatide should be avoided. Antiresorptive treatment with bisphosphonates or denosumab is presumed to be as effective in patients with NHPT as in postmenopausal women or older men. One study addressed antiresorptive treatment in NHPT [33]. Postmenopausal women were randomized to receive alendronate and cholecalciferol- or cholecalciferol-only for 12 months. Lumbar spine and total hip BMD improved in the alendronate and vitamin D3 cohort by $4.7 \%$ and $4.0 \%$, respectively, while BMD decreased significantly in the cholecalciferol-only group by $-1.6 \%$ and $-1.4 \%$, respectively. Bisphosphonates therefore seem to be safe and effective for the treatment of osteoporosis in NHPT.

\section{Nephrolithiasis}

The pathophysiology of kidney stones in PHPT has not completely been elucidated, but it is presumed to be strictly related to higher filtration of serum calcium through the kidney glomeruli, thus increasing urinary calcium and predisposing to crystal formation. However, when serum calcium is persistently normal, urine calcium might also be normal, and increased formation of kidney stones might not be expected.

In clinical practice, it is not yet clear that NHPT with hypercalciuria defined as 24-hour urinary calcium $>400 \mathrm{mg}$ should follow the same guidelines as those with mild PHPT. In NHPT, hypercalciuria could be a result of, or a determinant of NHPT.

In the previously mentioned cross-sectional study of the clinical profile of NHPT, Palermo et al. [30] evaluated the prevalence of nephrolithiasis through review of medical records. They found that $13 \%$ of patients with NHPT had kidney stones, as compared with $10 \%$ of patients with PHPT, without a signifi- cant difference between groups. Controls had a kidney stone prevalence of $3 \%$, although this figure may have been an underestimate since subjects were not systematically screened with abdominal imaging. These findings suggest comparable rates of nephrolithiasis between NHPT and PHPT; however, they still do not clarify the pathophysiology of kidney stones in hyperparathyroidism.

A study from Brazil reported that $20 \%$ of patients with NHPT undergoing abdominal ultrasound imaging had kidney stones [31]. This prevalence is higher than that reported in the general population of approximately $10.6 \%$ in the United States [34], but might be affected by selection bias, for example, caused by previous kidney stones.

If data about nephrolithiasis in NHPT are scarce, data on hypercalciuria, which should be excluded before making a diagnosis of NHPT, are even more so. Data regarding medical treatment of kidney stones appears inconclusive, although one study of 10 patients with NHPT suggested that the calcium-sensing receptor (CaSR) antagonist cinacalcet might reduce the number and size of kidney stones [35]. These data, though intriguing, need to be confirmed in larger prospective studies.

\section{NON-CLASSICAL COMPLICATIONS}

If it is assumed that the increased serum PTH level is the only driver of NHPT and its complications, this phenotype of parathyroid overactivity should allow an investigation of the effect of PTH excess in the absence of the confounding effect of increased serum calcium levels. Several cross-sectional studies have been published reporting associations of PTH excess with hypertension, cardiovascular risk factors, increased aldosterone, glycemic homeostasis, quality of life (QoL), and immune function. Table 2 summarizes these findings.

\section{Hypertension}

The pathophysiology of hypertension depends either on increased circulating blood volume or increased vascular resistance [36]. Increased PTH has been linked with both these factors. PTH1 receptors have been documented in human adrenal cortical cells [37]. One hypothesis presumes that PTH enhances release of aldosterone from the adrenal glands, thereby causing blood volume expansion. There also may be crosstalk between the parathyroid and adrenal glands, as mineralocorticoid receptors have been found on parathyroid cells [38]. It is not yet known whether there might be positive or negative feedback between these glands, and further studies are needed to clarify 


\begin{abstract}
Table 2. Non-Classical Manifestations of NHPT and Their Putative Mechanisms
Explanation

Hypertension

Aldosterone excess

Cardiovascular morbidity

Hyperglycemia

Quality of life (QoL)

Muscle function

Immune function and gut microbiota

PTH1R receptors on vascular cells may increase vascular tone, and, therefore resistance, leading to increased arterial blood pressure.

PTH levels correlate with aldosterone levels, with direct PTH stimulation of the adrenal glands.

Increased PTH levels have been associated with cardiovascular comorbidities. However, parathyroidectomy has not yet been shown to reduce cardiovascular comorbidity.

Increased PTH levels have been associated with insulin resistance and hyperglycemia. Parathyroidectomy has not yet been shown to improve $\mathrm{HbAlc}$, but may improve blood glucose levels.

Quality of life may be reduced in NHPT. Serum calcium levels may directly affect QoL, because surgery improves a number of domains of QoL if patients have preexisting mild hypercalcemia due to PHPT, compared to patients with normal serum calcium due to NHPT.

Muscle strength and function are impaired in patients with NHPT compared to healthy controls.

Immune function and gut microbiota may play a role in PHPT and NHPT as they may affect the severity of bone complications. This requires further investigation.
\end{abstract}

NHPT, normocalcemic primary hyperparathyroidism; PTH1R, parathyroid hormone 1 receptor; PTH, parathyroid hormone; HbA1c, glycated hemoglobin; PHPT, primary hyperparathyroidism.

the role of aldosterone in parathyroid disorders, and to exclude or confirm if aldosterone might be a pathophysiological factor in cardiovascular risk associated with hyperparathyroidism.

A recent study suggested that PTH may be directly related to central blood pressure, wave reflection, and systemic vascular resistance in patients without recognized cardiovascular comorbidities or medications affecting blood pressure [39]. Another study [40] found that $37 \%$ of 135 patients with primary aldosteronism had increased PTH levels, the majority of whom had normal serum calcium. Serum aldosterone and PTH levels were positively correlated in this study. Adrenal surgery or mineralocorticoid antagonists led to a reduction in PTH levels. The study concluded that PTH levels could be used to monitor treatment success in patients with autonomous aldosterone excess. This study, however, had several limitations, including its retrospective design and lack of measurement of serum 25(OH)D levels. Therefore, a direct connection between aldosterone and PTH still needs to be ascertained.

Another study from China found that NHPT subjects presented with higher blood pressure values compared to controls, but without persistently increased PTH levels [41]. The authors proposed a more aggressive approach to normalize PTH values independent of hypercalcemia.

\section{PTH AS A CARDIOVASCULAR RISK FACTOR}

The 2014 Fourth International Workshop on the Management of
Asymptomatic Primary Hyperparathyroidism [7] did not recommend parathyroid surgery to improve overall cardiovascular risk either for mild PHPT or NHPT because the evidence is scarce and somewhat contradictory. One study [42] showed that blood pressure, serum cholesterol, and homeostatic model assessment-insulin resistance (HOMA-IR) improved after parathyroidectomy. In contrast, another study [43], which evaluated the coronary calcium score did not find an association between NHPT and coronary artery disease. A recent study [44] compared 17 postmenopausal women with NHPT to 20 women with traditional PHPT and 20 controls. No differences were found in terms of echocardiographic parameters between these groups when stratified by degree of hypertension. Patients with obesity, diabetes, and previous cardiovascular disease were excluded. In this study, NHPT patients had higher serum phosphorus and lower PTH levels when compared with PHPT patients.

Based on existing data, PHPT may increase cardiovascular morbidity, but this risk has not yet been shown to improve with parathyroid surgery [45]. It is harder to assess cardiovascular risk in NHPT, but it is presumed that cardiovascular morbidity is not greater compared to PHPT, since PTH levels are lower or equal to those seen in the classical counterpart.

\section{GLUCOSE HOMEOSTASIS IN NHPT}

Few studies have investigated a putative association between increased PTH levels and glycemic control. One study seemed to exclude such an association, reporting that oral glucose toler- 
ance tests were comparable between NHPT patients and controls [28]. By contrast, another study found that PTH correlated positively with fasting blood glucose levels, suggesting that NHPT may be associated with impairment of glucose homeostasis [46]. The same investigators evaluated patients with NHPT and prediabetes undergoing parathyroid surgery or conservative follow-up for up to 8 months [47]. Both fasting and 2-hour post-load glucose levels improved in the group undergoing parathyroidectomy, while no differences noted in the group followed conservatively. However, neither glycated hemoglobin levels nor the homeostatic model assessment-beta cell function (HOMA-B) index changed in either group, likely reflecting a negligible impact of parathyroid surgery on these outcomes.

\section{PTH, immune cells, and microbiota}

There is growing interest in the regulation of immune cells by PTH and how the human microbiome may modulate the skeletal response to PTH [48]. In mice, continuous stimulation by PTH due to PHPT may cause bone loss by activating T-cells and interleukin 17 receptors, which in turn promote osteoclast activity [48]. However, this response may vary depending on the intestinal microbiome. This aspect is intriguing but requires further clinical investigation. In favor of the hypothesis that the immune system or the intestinal microbiome may affect the response of the skeleton to PTH is the fact that serum calcium does not always directly mediate skeletal effects of PHPT, because even in classical PHPT, some patients experience bone loss, while others do not. This hypothesis presumes that higher PTH levels might adversely affect the skeleton via other mediators, possibly including the gut microbiome.

\section{Quality of life and physical function of patients with NHPT}

Whether parathyroidectomy can improve QoL in patients with NHPT is still uncertain. Only one study has specifically addressed this issue [49]. Patients with NHPT were prospectively included if their serum calcium level was at the upper limit of normal with an inappropriately high PTH (>50 pg/mL). Serum calcium was assessed twice over a period of at least 3 weeks. QoL was assessed using a self-administered Short Form-36 v.2 Questionnaire (SF-36-v2). There was not a control group that did not undergo surgery, and the NHPT cohort was compared with a cohort with classical mild PHPT. NHPT patients improved in some QoL domains after surgery. There was an improvement in symptoms such as thirst, mood swings, and anxiety at 3 months, while only thirst was still improved at 6 months, and thirst and fatigue at 1 year. More symptoms im- proved in the mildly hypercalcemic cohort both at 3 and at 12 months. Although a control group was not included, this study suggested an association of symptoms with serum calcium, rather than PTH levels, with a continuum of symptoms correlating with serum calcium. This study did not address outcomes of surgery when serum calcium levels were normal or at the upper limit of normal. Nonetheless, it seems clear that patients with NHPT should not be routinely referred to surgery based on reduced QoL before surgery and expected improvement in QoL after surgery.

A recent study from Brazil evaluated both physical function and QoL in postmenopausal women with NHPT compared to those with PHPT and a control group of postmenopausal women without hyperparathyroidism [50]. The definition of NHPT relied on one assessment of albumin-adjusted serum calcium, without further measurements. Cases were selected by convenience sampling, and 13 patients with NHPT were evaluated. Physical performance was assessed by handgrip strength, chair stand test, gait speed, and the Short Physical Performance Battery. Participants also completed the Short Form Health Survey. The study showed for the first time that patients with NHPT had significant impairment in both muscle strength and performance compared to controls. When compared with PHPT, NHPT patients showed greater gait speed. Regarding QoL, patients with NHPT showed worse QoL in the general health perceptions domain compared to controls. This study suggests a link between high serum PTH levels and impairment in muscle function independent of hypercalcemia. The presence of parathyroid hormone 1 receptor (PTH1R) in skeletal muscle suggests that PTH over-secretion could directly affect muscle function.

A recent 10-year prospective observational study [51] suggested that a conservative approach might be as safe as parathyroid surgery in terms of QoL domains in mild PHPT. At present there are no data on which to base a recommendation for parathyroid surgery based on QoL alone in patients with NHPT, but these patients should be followed over time and monitored for symptoms.

\section{SURGERY}

Few data are available on outcomes of parathyroid surgery in NHPT. However, surgery in NHPT is more challenging for a variety of reasons. NHPT has been reported to have a higher prevalence of multigland disease [52], which may require multiple imaging technologies to detect the enlarged parathyroid glands, as these are often smaller than those found in classical 
PHPT [53]. Not only might it be more challenging to detect pathologic glands due to their smaller size, but there might be a greater risk of persistent disease after parathyroidectomy, so that targeted parathyroidectomy may not be sufficient. This would require that all patients with NHPT undergo systematic bilateral neck exploration (BNE) [52] to localize enlarged parathyroid glands, which may have been missed by parathyroid imaging. However, BNE is not without risk. Intraoperative PTH (ioPTH) may be helpful in these circumstances [52], but in NHPT the decline of ioPTH levels during parathyroidectomy might take longer than observed during surgery for classical PHPT [54]. Monitoring ioPTH would require longer operative times for parathyroidectomy in NHPT.

These observations do not indicate that parathyroidectomy may improve some of the complications of NHPT, as shown in a few studies investigating bone density change after parathyroidectomy [55], and reduction in the growth of previous kidney stones and prevention of new kidney stone formation [56]. However, disease remission becomes more difficult to define when patients may experience persistent hyperparathyroidism after parathyroidectomy. It is well known that recurrent hyperparathyroidism after parathyroid surgery is mostly due to low calcium intake or vitamin D insufficiency in the setting of overt or subclinical hungry-bones syndrome. However, if multigland disease is not uncommon in NHPT, it may be difficult to distinguish the etiology of hyperparathyroidism after surgery and to confirm that parathyroidectomy has been successful.

Long-term data regarding the effect of parathyroid surgery on complications in NHPT are not available. Caution should be used when selecting and referring patients to surgery unless both the endocrinologist and the surgeon feel that surgery is the best option for the patient.

\section{CONCLUSIONS}

Studies of NHPT have been heterogeneous regarding their definition of normal serum calcium. Few studies have rigorously followed the definition of NHPT provided by the Fourth International Workshop on the Management of Asymptomatic Primary Hyperparathyroidism, which requires that serum total or ionized calcium should be normal on repeated measurements over time. Albumin-corrected serum calcium has sometimes been used as a surrogate; however, most studies have included patients with few measurements of these biochemical factors, so that misclassification of NHPT as a milder form of classical PHPT is highly likely. Recent studies have shown that periodic oscillations of serum calcium just below and slightly above the upper limit of normal should be expected in this new phenotype of PHPT, especially when serum calcium is already in the highnormal range. There is debate if this biochemical pattern should be accepted as NHPT or simply a mild form of PHPT. It is important that serum $25(\mathrm{OH}) \mathrm{D}$ levels be greater than $30 \mathrm{ng} / \mathrm{mL}$ to define NHPT, and that all secondary causes of increased PTH be excluded to arrive at the correct diagnosis. As populationbased studies have shown, when serum calcium is consistently in the mid-normal range, it is most likely that an unrecognized secondary cause is driving the increase in PTH, rather than parathyroid gland autonomy. The best approach in these patients should be to monitor and treat classical and non-classical complications. The lack of robust prospective data on surgical outcomes suggests that parathyroidectomy should rarely be recommended and, in any case, chosen using a case-by-case approach. Non-classical complications, such as cardiovascular morbidity, should be investigated in prospective studies before reaching definitive conclusions.

\section{CONFLICTS OF INTEREST}

No potential conflict of interest relevant to this article was reported.

\section{ORCID}

Guido Zavatta https://orcid.org/0000-0003-3657-2070

Bart L. Clarke https://orcid.org/0000-0002-3801-9546

\section{REFERENCES}

1. Bilezikian JP, Khan AA, Potts JT Jr; Third International Workshop on the Management of Asymptomatic Primary Hyperthyroidism. Guidelines for the management of asymptomatic primary hyperparathyroidism: summary statement from the third international workshop. J Clin Endocrinol Metab 2009;94:335-9.

2. Silverberg SJ, Clarke BL, Peacock M, Bandeira F, Boutroy $\mathrm{S}$, Cusano NE, et al. Current issues in the presentation of asymptomatic primary hyperparathyroidism: proceedings of the Fourth International Workshop. J Clin Endocrinol Metab 2014;99:3580-94.

3. Cusano NE, Silverberg SJ, Bilezikian JP. Normocalcemic primary hyperparathyroidism. J Clin Densitom 2013;16:33-9.

4. Coe FL, Canterbury JM, Firpo JJ, Reiss E. Evidence for sec- 
ondary hyperparathyroidism in idiopathic hypercalciuria. $\mathrm{J}$ Clin Invest 1973;52:134-42.

5. Ross AC, Manson JE, Abrams SA, Aloia JF, Brannon PM, Clinton SK, et al. The 2011 report on dietary reference intakes for calcium and vitamin D from the Institute of Medicine: what clinicians need to know. J Clin Endocrinol Metab 2011;96:53-8.

6. Fuleihan Gel-H, Bouillon R, Clarke B, Chakhtoura M, Cooper C, McClung M, et al. Serum 25-hydroxyvitamin D levels: variability, knowledge gaps, and the concept of a desirable range. J Bone Miner Res 2015;30:1119-33.

7. Eastell R, Brandi ML, Costa AG, D’Amour P, Shoback DM, Thakker RV. Diagnosis of asymptomatic primary hyperparathyroidism: proceedings of the Fourth International Workshop. J Clin Endocrinol Metab 2014;99:3570-9.

8. Giustina A, Adler RA, Binkley N, Bouillon R, Ebeling PR, Lazaretti-Castro $\mathrm{M}$, et al. Controversies in vitamin D: summary statement from an international conference. J Clin Endocrinol Metab 2019;104:234-40.

9. Madeo B, De Vincentis S, Repaci A, Altieri P, Vicennati V, Kara E, et al. The calcium-to-phosphorous $(\mathrm{Ca} / \mathrm{P})$ ratio in the diagnosis of primary hyperparathyroidism and hypoparathyroidism: a multicentric study. Endocrine 2020;68: 679-87.

10. Schini M, Jacques RM, Oakes E, Peel NFA, Walsh JS, Eastell R. Normocalcemic hyperparathyroidism: study of its prevalence and natural history. J Clin Endocrinol Metab 2020;105:e1171-86.

11. Zaidan J, Wang X. Letter to the editor: "Normocalcemic hyperparathyroidism: study of its prevalence and natural history”. J Clin Endocrinol Metab 2020;105:dgaa275.

12. Schini M, Eastell R. Response to letter to the editor: "Normocalcemic hyperparathyroidism: study of its prevalence and natural history". J Clin Endocrinol Metab 2020;105: e2689.

13. Schini M, Jacques R, Oakes E, Peel N, Walsh JS, Eastell R. Normocalcaemic hyperparathyroidism and primary hyperparathyroidism: least significant change for adjusted serum calcium. Eur J Endocrinol 2021;184:K7-10.

14. Bland JM, Altman DG. Measurement error. BMJ 1996;313: 744.

15. Cusano NE, Maalouf NM, Wang PY, Zhang C, Cremers SC, Haney EM, et al. Normocalcemic hyperparathyroidism and hypoparathyroidism in two community-based nonreferral populations. J Clin Endocrinol Metab 2013;98:2734-41.

16. Lundgren E, Rastad J, Thrufjell E, Akerstrom G, Ljunghall
S. Population-based screening for primary hyperparathyroidism with serum calcium and parathyroid hormone values in menopausal women. Surgery 1997;121:287-94.

17. Berger C, Almohareb O, Langsetmo L, Hanley DA, Kovacs CS, Josse RG, et al. Characteristics of hyperparathyroid states in the Canadian multicentre osteoporosis study (CaMos) and relationship to skeletal markers. Clin Endocrinol (Oxf) 2015;82:359-68.

18. Kontogeorgos G, Trimpou P, Laine CM, Olerod G, Lindahl A, Landin-Wilhelmsen K. Normocalcaemic, vitamin D-sufficient hyperparathyroidism: high prevalence and low morbidity in the general population. A long-term follow-up study, the WHO MONICA project, Gothenburg, Sweden. Clin Endocrinol (Oxf) 2015;83:277-84.

19. Garcia-Martin A, Reyes-Garcia R, Munoz-Torres M. Normocalcemic primary hyperparathyroidism: one-year followup in one hundred postmenopausal women. Endocrine 2012;42:764-6.

20. Amaral LM, Queiroz DC, Marques TF, Mendes M, Bandeira F. Normocalcemic versus hypercalcemic primary hyperparathyroidism: more stone than bone? J Osteoporos 2012; 2012:128352.

21. Maruani G, Hertig A, Paillard M, Houillier P. Normocalcemic primary hyperparathyroidism: evidence for a generalized target-tissue resistance to parathyroid hormone. J Clin Endocrinol Metab 2003;88:4641-8.

22. Tordjman KM, Greenman Y, Osher E, Shenkerman G, Stern $\mathrm{N}$. Characterization of normocalcemic primary hyperparathyroidism. Am J Med 2004;117:861-3.

23. Silverberg SJ, Bilezikian JP. "Incipient" primary hyperparathyroidism: a "forme fruste" of an old disease. J Clin Endocrinol Metab 2003;88:5348-52.

24. Lowe H, McMahon DJ, Rubin MR, Bilezikian JP, Silverberg SJ. Normocalcemic primary hyperparathyroidism: further characterization of a new clinical phenotype. J Clin Endocrinol Metab 2007;92:3001-5.

25. Wade TJ, Yen TW, Amin AL, Wang TS. Surgical management of normocalcemic primary hyperparathyroidism. World J Surg 2012;36:761-6.

26. Koumakis E, Souberbielle JC, Sarfati E, Meunier M, Maury E, Gallimard E, et al. Bone mineral density evolution after successful parathyroidectomy in patients with normocalcemic primary hyperparathyroidism. J Clin Endocrinol Metab 2013;98:3213-20.

27. Marques TF, Vasconcelos R, Diniz E, Rego D, Griz L, Bandeira F. Normocalcemic primary hyperparathyroidism in 
clinical practice: an indolent condition or a silent threat? Arq Bras Endocrinol Metabol 2011;55:314-7.

28. Cakir I, Unluhizarci K, Tanriverdi F, Elbuken G, Karaca Z, Kelestimur F. Investigation of insulin resistance in patients with normocalcemic primary hyperparathyroidism. Endocrine 2012;42:419-22.

29. Siprova H, Frysak Z, Soucek M. Primary hyperparathyroidism, with a focus on management of the normocalcemic form: to treat or not to treat? Endocr Pract 2016;22:294-301.

30. Palermo A, Naciu AM, Tabacco G, Falcone S, Santonati A, Maggi D, et al. Clinical, biochemical, and radiological profile of normocalcemic primary hyperparathyroidism. J Clin Endocrinol Metab 2020;105:dgaa174.

31. Lemos ALP, Andrade SRL, Pontes LLH, Teixeira PMC, Bandeira E, Bandeira LC, et al. High rate of occult urolithiasis in normocalcemic primary hyperparathyroidism. Kidney Blood Press Res 2019;44:1189-95.

32. Silverberg SJ, Shane E, Jacobs TP, Siris E, Bilezikian JP. A 10-year prospective study of primary hyperparathyroidism with or without parathyroid surgery. N Engl J Med 1999; 341:1249-55.

33. Cesareo R, Di Stasio E, Vescini F, Campagna G, Cianni R, Pasqualini V, et al. Effects of alendronate and vitamin D in patients with normocalcemic primary hyperparathyroidism. Osteoporos Int 2015;26:1295-302.

34. Tang J, Mettler P, McFann K, Chonchol M. The association of prevalent kidney stone disease with mortality in US adults: the National Health and Nutrition Examination Survey III, 1988-1994. Am J Nephrol 2013;37:501-6.

35. Brardi S, Cevenini G, Verdacchi T, Romano G, Ponchietti R. Use of cinacalcet in nephrolithiasis associated with normocalcemic or hypercalcemic primary hyperparathyroidism: results of a prospective randomized pilot study. Arch Ital Urol Androl 2015;87:66-71.

36. Saxena T, Ali AO, Saxena M. Pathophysiology of essential hypertension: an update. Expert Rev Cardiovasc Ther 2018; 16:879-87.

37. Rossi GP, Lenzini L. Vitamin D supplementation: a novel therapy for aldosteronism? Nat Rev Endocrinol 2020;16: 303-4.

38. Tomaschitz A, Ritz E, Pieske B, Rus-Machan J, Kienreich K, Verheyen N, et al. Aldosterone and parathyroid hormone interactions as mediators of metabolic and cardiovascular disease. Metabolism 2014;63:20-31.

39. Oinonen L, Tikkakoski A, Koskela J, Eraranta A, Kahonen $\mathrm{M}$, Niemela $\mathrm{O}$, et al. Parathyroid hormone may play a role in the pathophysiology of primary hypertension. Endocr Connect 2021;10:54-65.

40. Kometani M, Yoneda T, Aono D, Gondoh-Noda Y, Matsuoka T, Higashitani T, et al. Primary aldosteronism with parathyroid hormone elevation: a single-center retrospective study. Intern Med 2021;60:993-8.

41. Chen G, Xue Y, Zhang Q, Xue T, Yao J, Huang H, et al. Is normocalcemic primary hyperparathyroidism harmful or harmless? J Clin Endocrinol Metab 2015;100:2420-4.

42. Beysel S, Caliskan M, Kizilgul M, Apaydin M, Kan S, Ozbek M, et al. Parathyroidectomy improves cardiovascular risk factors in normocalcemic and hypercalcemic primary hyperparathyroidism. BMC Cardiovasc Disord 2019;19:106.

43. Mesquita PN, Dornelas Leao Leite AP, Chagas Crisostomo SD, Veras Filho E, da Cunha Xavier L, Bandeira F. Evaluation of coronary calcium score in patients with normocalcemic primary hyperparathyroidism. Vasc Health Risk Manag 2017;13:225-9.

44. Pepe J, Colangelo L, Sonato C, Occhiuto M, Ferrara C, Del Fattore A, et al. Echocardiographic findings in patients with normocalcemic primary hyperparathyroidism compared with findings in hypercalcemic primary hyperparathyroid patients and control subjects. Endocr Pract 2021;27:21-6.

45. Bollerslev J, Sjostedt E, Rejnmark L. Cardiovascular consequences of parathyroid disorders in adults. Ann Endocrinol (Paris) 2021;82:151-7.

46. Karras SN, Koufakis T, Tsekmekidou X, Antonopoulou V, Zebekakis P, Kotsa K. Increased parathyroid hormone is associated with higher fasting glucose in individuals with normocalcemic primary hyperparathyroidism and prediabetes: a pilot study. Diabetes Res Clin Pract 2020;160:107985.

47. Karras S, Annweiler C, Kiortsis D, Koutelidakis I, Kotsa K. Improving glucose homeostasis after parathyroidectomy for normocalcemic primary hyperparathyroidism with co-existing prediabetes. Nutrients 2020;12:3522.

48. Pacifici R. Role of gut microbiota in the skeletal response to PTH. J Clin Endocrinol Metab 2021;106:636-45.

49. Bannani S, Christou N, Guerin C, Hamy A, Sebag F, Mathonnet $\mathrm{M}$, et al. Effect of parathyroidectomy on quality of life and non-specific symptoms in normocalcaemic primary hyperparathyroidism. Br J Surg 2018;105:223-9.

50. Voss L, Nobrega M, Bandeira L, Griz L, Rocha-Filho PAS, Bandeira F. Impaired physical function and evaluation of quality of life in normocalcemic and hypercalcemic primary hyperparathyroidism. Bone 2020;141:115583.

51. Pretorius M, Lundstam K, Hellstrom M, Fagerland MW, 
Godang K, Mollerup C, et al. Effects of parathyroidectomy on quality of life: 10 years of data from a prospective randomized controlled trial on primary hyperparathyroidism (the SIPH-Study). J Bone Miner Res 2021;36:3-11.

52. Pandian TK, Lubitz CC, Bird SH, Kuo LE, Stephen AE. Normocalcemic hyperparathyroidism: a Collaborative Endocrine Surgery Quality Improvement Program analysis. Surgery 2020;167:168-72.

53. Trinh G, Rettig E, Noureldine SI, Russell JO, Agrawal N, Mathur A, et al. Surgical management of normocalcemic primary hyperparathyroidism and the impact of intraoperative parathyroid hormone testing on outcome. Otolaryngol
Head Neck Surg 2018;159:630-7.

54. Graves CE, McManus CM, Chabot JA, Lee JA, Kuo JH. Biochemical profile affects IOPTH kinetics and cure rate in primary hyperparathyroidism. World J Surg 2020;44:488-95.

55. Sho S, Kuo EJ, Chen AC, Li N, Yeh MW, Livhits MJ. Biochemical and skeletal outcomes of parathyroidectomy for normocalcemic (incipient) primary hyperparathyroidism. Ann Surg Oncol 2019;26:539-46.

56. Traini E, Bellantone R, Tempera SE, Russo S, De Crea C, Lombardi CP, et al. Is parathyroidectomy safe and effective in patients with normocalcemic primary hyperparathyroidism? Langenbecks Arch Surg 2018;403:317-23. 